\title{
Investigation of Lateral Epicondylitis in Neurosurgeons
}

\author{
Omer POLAT'1 ${ }^{1}$, Cengiz TUNCER ${ }^{1}$, Yusuf Alper KATI², Ozhan Merzuk UCKUN³, Uygur ER ${ }^{1}$ \\ ${ }^{1}$ Duzce University, School of Medicine, Department of Neurosurgery, Duzce, Turkey \\ ${ }^{2}$ Antalya Training and Research Hospital, Department of Orthopedics and Traumatology, Antalya, Turkey \\ ${ }^{3}$ Ankara Numune Training and Research Hospital, Department of Neurosurgery, Ankara,Turkey
}

Corresponding author: Omer POLAT polatnrs@gmail.com

\section{ABSTRACT}

AIM: To investigate the frequency of lateral epicondylitis (LE), depending on the tasks performed by neurosurgeons, and to determine whether it can be accepted as an occupational disease depending on its frequency.

MATERIAL and METHODS: All neurosurgery specialists enrolled in the Turkish Neurosurgical Society website were prospectively included. A questionnaire form was shared, and the subsequent responses were recorded. Those who provided incomplete responses were excluded from the study. The respondents diagnosed with LE were recorded. Exclusion criteria were investigated on complaints of pain. They were examined by an orthopedics and traumatology specialist with application of Thomsen test and necessary maneuvers.

RESULTS: The study was conducted with 216 neurosurgeons. Those with more than 30 operations per month $(p=0.002)$, those with a specialization duration of $10-20$ years and $>20$ years $(p=0.001)$, and those who specialized in spinal surgery $(p=0.014)$ had a significantly higher prevalence of epicondylitis. Considering the relationship between lumbar/thoracic pedicle screw insertion and epicondylitis, the epicondylitis diagnosis rate was significantly higher in physicians inserting 20-60 screws per month than those inserting <20 screws $(\mathrm{p}=0.009)$.

CONCLUSION: LE frequently occurs in neurosurgeons who regularly perform spinal instrumentation and appears to be an occupational disease. However, data obtained during the current study should be combined with findings from case-control studies of neurosurgeons.

KEYWORDS: Lateral epicondylitis, Neurosurgeon, Occupational disease, Neurosurgery

\section{INTRODUCTION}

L ateral epicondylitis (LE) is form of tendinitis that was first identified in 1873 and is characterized by pain on the lateral epicondyle, from which wrist extensor muscles originate, and on the forearm extensor muscle surface. It is one of the most common arm injuries, can lead to chronic pain syndrome, and is frequently referred to as tennis elbow (21). It has been observed in people who perform activities involving repetitive wrist extensions and can cause pain and reduced grip strength, while limiting execution of activities of daily living $(1,22)$.

Studies have shown that LE is associated with occupational activities requiring physical strength $(12,15,17,19,21)$. The risk is further increased in the presence of excessive force and inappropriate posture, in addition to frequent repetition $(4,6,7,18)$. The prevalence of LE in workers whose jobs require repetitive work ranges from $1.3 \%$ to $12.2 \%$ (10). LE has been defined as an occupational disease due to its increased workrelated incidence, although its prevalence is low in general population $(0.7 \%-4.0 \%)$. LE has been considered, under the category of musculoskeletal diseases, among the top occupational diseases $(2,16,18)$.

There have been a limited number of studies investigating occupational diseases in doctors, particularly in surgeons $(9,11,13)$. LE was detected in $13.5 \%$ of participants in a study investigating musculoskeletal occupational diseases in plastic surgeons (3). However, there have been no studies of LE in neurosurgeons, even though these professionals use an increasing number of instruments during surgeries.
Omer POLAT (10): 0000-0003-4521-4312

Cengiz TUNCER (1): 0000-0003-2400-5546

Yusuf Alper KATI (1) : 0000-0003-2706-3813
Ozhan Merzuk UCKUN (10): 0000-0002-3845-2665

Uygur ER (D): 0000-0002-6641-0075 
This study aimed to investigate the frequency of LE in neurosurgeons and to discuss its acceptance as an occupational disease.

\section{MATERIAL and METHODS}

This study was prospectively conducted between March and May 2018 and was approved by the Duzce University Ethics Committee. The study included all neurosurgery specialists indexed on the Turkish Neurosurgical Society website, excluding physician associates. A questionnaire form consisting of 9 questions was shared through the society mail group and with return service requested. Only those who provided complete responses were included in the study. The respondents that were previously diagnosed with LE were recorded. Exclusion criteria were investigated on accessible specialists with and without pain complaint. These individuals were examined by an orthopedics and traumatology specialist who applied the Thomsen test and other necessary maneuvers.

Exclusion criteria were pregnancy, involvement in sport activities (playing tennis), cervical spondylosis, discopathy, radiculopathy, presence of myelopathy, upper extremity (shoulder, elbow) arthritis history, rotator cuff damage, presence of rheumatic diseases, systemic disease, peripheral nerve compression in the upper extremity (carpal tunnel, cubital tunnel, radial nerve compression), and history of previous elbow dislocation or elbow surgery.

Those diagnosed following examination were recorded. Those who complained but could not be examined by the orthopedics and traumatology specialist were excluded from the study. All data were compared.

Statistical analyses were performed using SPSS version 20.0 for Windows (SPSS Inc., Chicago, IL, USA). Continuous variables are expressed as means \pm standard deviations and categorical variables are presented as percentages. Nonparametric variables were compared using a chi-square test, and Fisher's exact test was used when indicated. The Bonferroni test was used to detect the differences between subgroups. A $p$-value of $<0.05$ was considered as statistically significant.

\section{RESULTS}

There were a total of 216 neurosurgeons: 204 males (94.4\%) and 12 females $(5.6 \%)$. There were 75 surgeons $(34.7 \%)$ with specialization durations of $6-10$ years. There were 87 (40.3\%) surgeons who completed 11-20 operations per month, and $179(82.9 \%)$ of respondents used anywhere from 0 to 10 instruments. We inquired the number of lumbar/thoracic pedicle screws used per month and found that 108 participants (50\%) reported using 0-20 screws. A total of 109 (50.5\%) neurosurgeons reported experiencing elbow pain at least once per year, and 43 surgeons (19.9\%) reported workforce loss due to elbow pain. Upon orthopedic examination, 81 $(37.5 \%)$ neurosurgeons were diagnosed with epicondylitis. Of the 81 diagnosed with epicondylitis, $59(72.83 \%)$ reported receiving treatment for the condition. Neurosurgeons reported using their right hands $93.5 \%$ of the time. Interestingly, $46.8 \%$
Table I: Neurosurgeons' Years of Specialization, Number and Characteristics of Surgeries, and Elbow Complaints

\begin{tabular}{lrr}
\hline & $\mathbf{n}$ & $\%$ \\
\hline Duration of specialization (year) & & \\
\hline $0-2$ & 11 & 5.1 \\
\hline $3-5$ & 35 & 16.2 \\
\hline $6-10$ & 75 & 34.7 \\
\hline $11-20$ & 55 & 25.5 \\
\hline Over 20 & 40 & 18.5 \\
\hline Number of operations / month & & \\
\hline $0-10$ & 41 & 19.0 \\
\hline $11-20$ & 87 & 40.3 \\
\hline $21-30$ & 59 & 27.3 \\
\hline Over 30 & 29 & 13.4 \\
\hline Instrumented surgery / month & & \\
\hline $0-10$ & 179 & 82.9 \\
\hline $11-20$ & 35 & 16.2 \\
\hline $21-30$ & 2 & 0.9 \\
\hline
\end{tabular}

Number of lumbar/thoracic pedicle screws used per month

\begin{tabular}{lrr}
\hline $0-20$ & 108 & 50.0 \\
\hline $21-60$ & 80 & 37.0 \\
\hline $61-100$ & 26 & 12.0 \\
\hline Over 100 & 2 & 0.9 \\
\hline
\end{tabular}

\section{Elbow pain frequency}

\begin{tabular}{lrr}
\hline Week & 30 & 13.9 \\
\hline Month & 77 & 35.6 \\
\hline Year & 109 & 50.5 \\
\hline
\end{tabular}

\section{Workforce loss due to elbow pain}

\begin{tabular}{crc}
\hline Yes & 43 & 19.9 \\
\hline No & 173 & 80.1 \\
\hline
\end{tabular}

Epicondylitis treatment

\begin{tabular}{lrr}
\hline Yes & 59 & 27.3 \\
\hline No & 157 & 72.7 \\
\hline
\end{tabular}

\section{Dominant hand}

\begin{tabular}{lrr}
\hline Right & 202 & 93.5 \\
\hline Left & 12 & 5.6 \\
\hline Both & 2 & 0.9 \\
\hline
\end{tabular}

Subspecialty

\begin{tabular}{lrr}
\hline Spinal surgery & 101 & 46.8 \\
\hline Cranial surgery & 19 & 8.8 \\
\hline Both & 96 & 44.4 \\
\hline
\end{tabular}


exclusively operated on the spine, while $44.4 \%$ operated on both the brain and spine. All the data related to neurosurgeons are shown in Table I.

Examining elbow pain, neurosurgeons who averaged more than 30 operations per month $(46.7 \%)$ reported a significantly higher frequency of weekly elbow pain than other subgroups $(p<0.0001)$. Additionally, the frequency of weekly elbow pain was significantly higher among those with $>20$ years of experience $(40 \%)$ than those with $2-5(3.3 \%)$ or $6-10$ years of experience $(16.7 \%)(p<0.0001)$. Elbow pain was present in $73.3 \%$ of neurosurgeons who performed weekly spinal surgeries, in $44.2 \%$ of those who performed spinal surgeries at least once per month, and in $41.3 \%$ of those who performed at least one spinal surgery per year. These rates were significantly higher than those observed among surgeons who routinely performed cranial surgeries $(p<0.0001)$. As the number of surgeries with instruments increased, the incidence of elbow pain significantly increased. At least one or more episodes of elbow pain per week were observed in $70 \%$ of those who performed 0-10 surgeries per month (using instruments), $85.7 \%$ of those who performed $11-20$ operations, and $84.4 \%$ of those who performed 21-30 operations $(p=0.041)$. The frequency of elbow pain did not vary relative to the frequency with which pedicle screws were inserted ( $p>0.05)$ (Table II). The rate of missed work due to elbow pain was significantly higher among neurosurgeons who predominately performed spinal surgeries $(58.5 \%)$, with $65.9 \%$ of those who reported inserting 21-60 pedicle screws per month reporting missed work secondary to elbow pain.

Epicondylitis diagnosis was diagnosed with a significantly higher frequency among those surgeons who performed $>30$ surgeries per month (23.5\%) than those who performed 0-10 surgeries per month $(11.1 \%)(p=0.002)$. The frequency with which epicondylitis was diagnosed appeared to vary relative to duration of specialization, with significantly different rates for those with 2-5 years' (7.4\%) experience, compared with those with $11-20$ years $(32.1 \%)$, and $>20$ years $(28.4 \%)(p=0.001)$. The rate of epicondylitis diagnosis was significantly higher

Table II: Relationship of Elbow Pain Frequency with Other Data

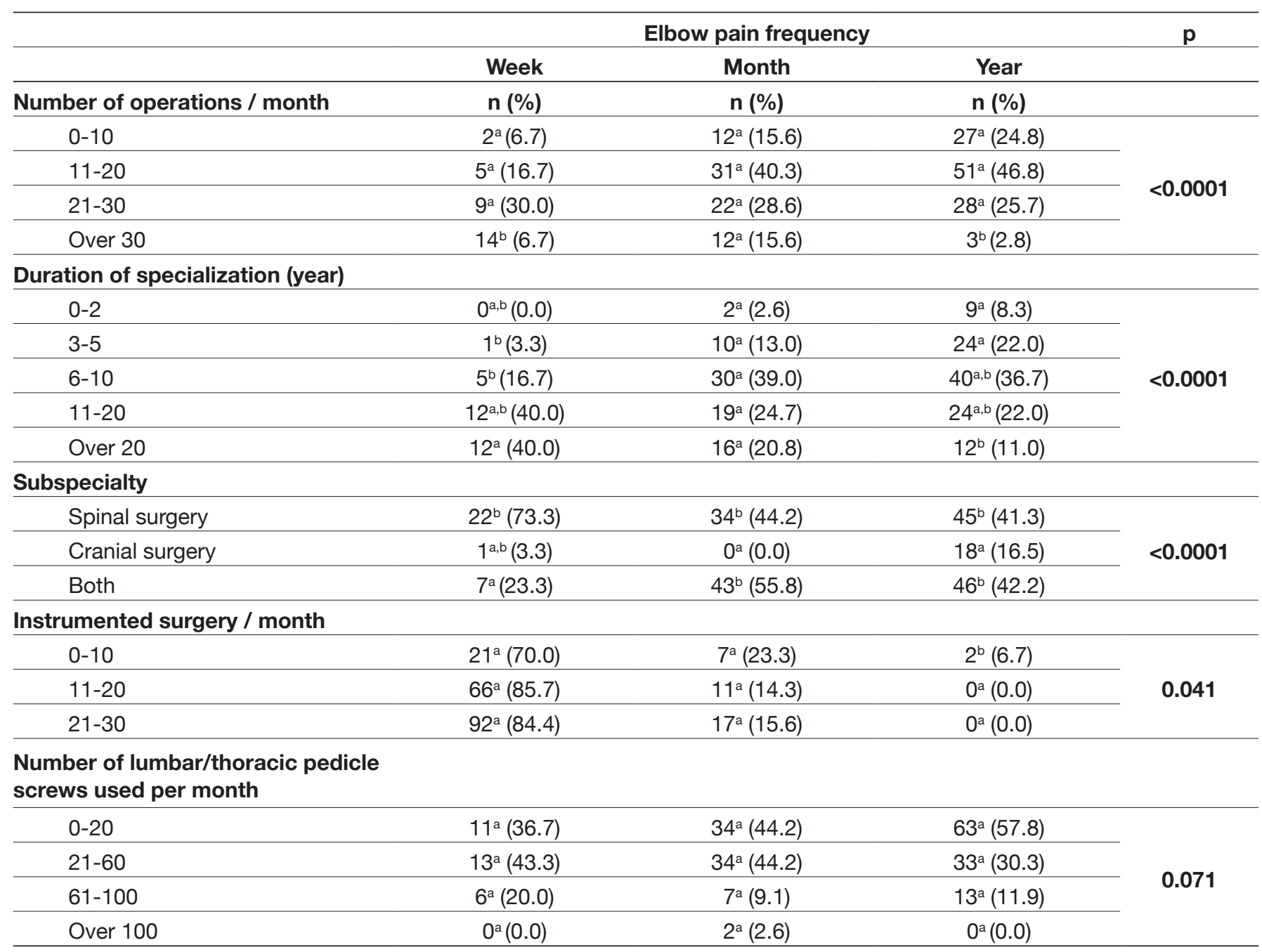

The Bonferroni test was used to compare the differences between subgroups shown in the line. ${ }^{a, b}$ : The mean differences were significant at the 0.05 level. 
among specialists who primarily performed spinal surgeries $(58 \%) \quad(p=0.014)$. Investigating the relationship between lumbar/thoracic pedicle screw insertion and epicondylitis, the epicondylitis diagnosis rate was significantly higher in surgeons who inserted 21-60 screws per month (50.6\%) than those who inserted $<20$ screws $(40.7 \%)(p=0.009)$ (Table III).

Those who performed 11-20 or more operations per month underwent epicondylitis treatment significantly more frequently than comparator groups $(p<0.0001)$. The frequency of epicondylitis treatment was significantly lower among those with specialization durations of $2-5$ years than those with $6-10$, $11-20$, or $>20$ years' experience $(0.0 \%)(p<0.0001)$. The rate of epicondylitis treatment was high among specialists dealing with spinal surgery $(52.5 \%)(p=0.018)$; however, no cranial surgery practitioners were diagnosed with epicondylitis (Table IV).

\section{DISCUSSION}

LE is associated with occupational activities requiring physical strength $(2,5)$. van Rijn et al. reported that LE was more frequently observed in those who loaded over $20 \mathrm{~kg}$, more than 10 times per day, those who performed repetitive elbow movements for more than 2 hours per day, those engaged in spinning and screwing activities, and those who worked with their arms in front of their bodies, during part of the business day (19). Repetitive activities are more associated with symptom onset than with the magnitude of strength required to perform activities. Partial or complete tendon tear develops as a result of excessive use due to repetitive microtraumas. Extensor muscles remain under extreme stress and symptoms occur as a result of forced movements, performed by those whose jobs require continuous wrist gripping, swinging movements like supination-pronation, or in cases of people engaged in sports

Table III: Relationship of Epicondylitis Diagnosis with Other Data

\begin{tabular}{|c|c|c|c|}
\hline & \multicolumn{3}{|c|}{ Epicondylitis diagnosis } \\
\hline & Yes & No & $\mathbf{p}$ \\
\hline Number of operations / month & n (\%) & n (\%) & \\
\hline $0-10$ & $9^{a}(11.1)$ & $32^{\mathrm{a}}(23.7)$ & \multirow{4}{*}{0.00} \\
\hline $11-20$ & $34^{\mathrm{a}, \mathrm{b}}(42.0)$ & $53^{\mathrm{a}, \mathrm{b}}(39.3)$ & \\
\hline $21-30$ & $19^{a}(23.5)$ & $40^{a}(29.6)$ & \\
\hline Over 30 & $19^{\mathrm{b}}(23.5)$ & $10^{\mathrm{b}}(7.4)$ & \\
\hline \multicolumn{4}{|l|}{ Duration of specialization (year) } \\
\hline $0-2$ & $2^{a, b}(2.5)$ & $9^{a, b}(6.7)$ & \multirow{5}{*}{0.00} \\
\hline $3-5$ & $6^{\mathrm{b}}(7.4)$ & $29^{\mathrm{b}}(21.5)$ & \\
\hline $6-10$ & $24^{\mathrm{a}, \mathrm{b}}(29.6)$ & $51^{\mathrm{a}, \mathrm{b}}(37.8)$ & \\
\hline $11-20$ & $26^{\mathrm{a}}(32.1)$ & $29^{a}(21.5)$ & \\
\hline Over 20 & $23^{a}(28.4)$ & $17^{\mathrm{a}}(12.6)$ & \\
\hline \multicolumn{4}{|l|}{ Subspecialty } \\
\hline Spinal surgery & $47^{\mathrm{b}}(58.0)$ & $54^{\mathrm{b}}(40.0)$ & \multirow{3}{*}{0.014} \\
\hline Cranialsurgery & $3^{\mathrm{a}}(3.7$ & $16^{\mathrm{a}}(11.9)$ & \\
\hline Both & $31^{a, b}(38.3)$ & $65^{\mathrm{a}, \mathrm{b}}(48.1)$ & \\
\hline \multicolumn{4}{|l|}{ Instrumented surgery / month } \\
\hline $0-10$ & $65^{a}(80.2)$ & $114^{\mathrm{a}}(84.4)$ & \multirow{3}{*}{0.188} \\
\hline $11-20$ & $14^{a}(17.3)$ & $21^{a}(15.6)$ & \\
\hline $21-30$ & $2^{\mathrm{a}}(2.5)$ & $0^{\mathrm{a}}(0.0)$ & \\
\hline \multicolumn{4}{|c|}{ Number of lumbar/thoracic pedicle screws used per month } \\
\hline $0-20$ & $33^{a}(40.7)$ & $75^{\mathrm{a}}(55.6)$ & \multirow{4}{*}{0.009} \\
\hline $21-60$ & $41^{\mathrm{b}}(50.6)$ & $39^{\mathrm{b}}(28.9)$ & \\
\hline $61-100$ & $7^{\mathrm{a}, \mathrm{b}}(8.6)$ & $19^{a, b}(14.1)$ & \\
\hline Over 100 & $0^{a, b}(0.0)$ & $2^{\mathrm{a}, \mathrm{b}}(1.5)$ & \\
\hline
\end{tabular}

The Bonferroni test was used to compare the differences between subgroups shown in the line. ${ }^{a, b}$ : The mean differences were significant at the 0.05 level. 
activities that require similar movements $(6,14)$. Other studies have focused on work duration. Hagberg reported increased frequency of $L E$ associated with age among those engaged in the same line of work for $>10$ years (8).

It has been reported that $25.1 \%$ of blue-collar workers, $10.5 \%$ of low-level white-collar workers, and $4.7 \%$ of managers are exposed to flexion/extension involving the elbows, wrist bending, and high physical strain, thus paving way for LE (10). Surgeons are considered both white- and blue-collar workers because their area of work is technically and physically difficult and requires rigor and high endurance (3). Common surgical work-related risks include sharp object injuries, blood-borne diseases, latex allergies, exposure to dangerous chemicals and anesthetic gases, equipment-related risks, radiation exposure, maintenance of static postures, and work-related stressors (13). Surgeons also are at increased risk of developing serious musculoskeletal disorders when operating positions are not properly adjusted (9). Among all surgeons, occupational diseases likely occur more frequently in neurosurgeons since they have to endure taxing work conditions. However, occupational diseases associated with the neurosurgical profession are not reported in the literature. LE reportedly affected $13.5 \%$ participants in a study of musculoskeletal occupational diseases among 325 plastic surgeons working in similar conditions (3)

Together with an increased number of surgeries with instruments, many features related to LE (performance of repetitive elbow movements for more than 2 hours per day, performing spinning and screwing activities, working with arms in front of the body, working with twisted wrists, and doing sensitive

Table IV: Relationship of Receiving Epicondylitis Treatment with Other Data

\begin{tabular}{|c|c|c|c|}
\hline & \multicolumn{3}{|c|}{ Epicondylitis treatment } \\
\hline Number of operations / month & n (\%) & n (\%) & \\
\hline $0-10$ & $4^{a}(6.8)$ & $37^{\mathrm{a}}(23.6)$ & \multirow{3}{*}{$<0.0001$} \\
\hline $11-20$ & $24^{a}(40.7)$ & $63^{\mathrm{a}}(40.1)$ & \\
\hline Over 30 & $17^{\mathrm{b}}(28.8)$ & $12^{\mathrm{b}}(7.6)$ & \\
\hline \multicolumn{4}{|l|}{ Duration of specialization (year) } \\
\hline $0-2$ & $2^{\mathrm{a}, \mathrm{b}}(3.4)$ & $9^{a, b}(5.7)$ & \multirow{2}{*}{$<0.0001$} \\
\hline $3-5$ & $0^{\mathrm{b}}(0.0)$ & $35^{\mathrm{b}}(22.3)$ & \\
\hline \multicolumn{4}{|l|}{ Subspecialty } \\
\hline Spinal surgery & $31^{\mathrm{b}}(52.5)$ & $70^{\mathrm{b}}(44.6)$ & \multirow{3}{*}{0.018} \\
\hline Cranial surgery & $0^{a}(0.0)$ & $19^{a}(12.1)$ & \\
\hline Both & $28^{\mathrm{b}}(47.5)$ & $68^{\mathrm{b}}(43.3)$ & \\
\hline \multicolumn{4}{|l|}{ Instrumented surgery / month } \\
\hline $0-10$ & $46^{\mathrm{a}}(78.0)$ & $133^{a}(84.7)$ & \multirow[b]{2}{*}{0.073} \\
\hline $11-20$ & $11^{\mathrm{a}}(18.6)$ & $24^{a}(15.3)$ & \\
\hline Over 100 & $0^{\mathrm{a}}(0.0)$ & $2^{\mathrm{a}}(1.3)$ & 0.402 \\
\hline
\end{tabular}

The Bonferroni test was used to compare the differences between subgroups shown in the line. ${ }^{a, b}$ : The mean differences were significant at the 0.05 level. 
work during part of the business day) that were described by van Rijn et al. are also observed, sometimes routinely, among neurosurgeons.

In our study, LE was detected in a very high proportion (37.5\%) of neurosurgeons. Of those diagnosed with LE, $72.83 \%$ also reported receiving treatment. When factors affecting the frequency of LE were examined, LE was more frequently observed among those who operated more than 30 times per month, who specialized in their field of practice for more than 10 years, and those who practiced spinal surgery. In addition, prevalence of epicondylitis was higher among neurosurgeons who used more instruments (21-60 screws per month). Repetitive supine-pronation movements, resulting from the application of force during tightening of pedicle screws used during spinal operations, trigger LE. This is also supported by data that showed that more cases of epicondylitis were diagnosed as the number of inserted screws increased. Based on these data, LE can be considered an occupational disease disproportionately affecting neurosurgeons.

To date, no universally accepted regimen of treatment exists; however some general principles of treatment should be taken into consideration. The treatment of LE should be oriented to the management of pain, preservation of movement, improvement in grip strength and endurance, return to normal function and control of further clinical deterioration (20).

The limitations of this study were the study cohort size and lack of additional precautions that eliminate more interests of those with LE. Moreover, we did not compare males and females since there were few female neurosurgeons in our country at the time of the study.

\section{CONCLUSION}

LE predominantly affects neurosurgeons who perform spinal instrumentation, supporting the idea that LE is an occupational disease. We attribute the incidence of LE among neurosurgeons to microtraumas inflicted due to the epicondylitis, caused because of application of right helix pedicle screwing and repetitive movements. LE may be prevented with safe utilization of navigation for pedicle screw delivery and low speed engines, which are promising additions to contemporary spinal surgeries. We also think that use of the left helix screw can also reduce loading on the epicondyle because of the large number of specialists who use their right hands during manual pedicle screw application. However, our findings should be supported by case-control studies of neurosurgeons.

\section{- REFERENCES}

1. Alizadehkhaiyat $O$, Fisher AC, Kemp GJ, Frostick SP: Pain, functional disability, and psychologic status in tennis elbow. Clin J Pain 23:482-489,2007

2. Bepko J, Mansalis K: Common occupational disorders: Asthma, COPD, dermatitis, and musculoskeletal disorders. Am Fam Physician 93:1000-1006,2016
3. Capone AC, Parikh PM, Gatti ME, Davidson BJ, Davison SP: Occupational injury in plastic surgeons. Plast Reconstr Surg125:1555-1561, 2010

4. Chiang HC, Ko YC, Chen SS, Yu HS, Wu TN, Chang PY: Prevalence of shoulder and upper-limb disorders among workers in the fish-processing industry. Scand J Work Environ Health 19:126-131, 1993

5. Descatha A, Dale AM, Silverstein BA, Roquelaure Y, Rempel D: Lateral epicondylitis: New evidence for work relatedness. Joint Bone Spine 82:5-7,2015

6. Fan ZJ, Silverstein BA, Bao S, Bonauto DK, Howard NL, Smith CK: Theassociation between combination of hand force and forearm posture and incidence of lateral epicondylitis in a working population. Hum Factors 56:151-165,2014

7. Haahr JP, Andersen JH: Physical and psychosocial risk factors for lateral epicondylitis: A population based case-referent study. Occup Environ Med 60:322-329,2003

8. Hagberg M: Clinical assessment of musculoskeletal disorders in workers exposed to hand-arm vibration. Int Arch Occup Environ Health 75:97-105, 2002

9. Hermanson JE, Choi SD: Study of musculoskeletal risks of the office-based surgeries. Work 41:1940-1943,2012

10. Herquelot E, Bodin J, Roquelaure Y, Ha C, Leclerc A, Goldberg M, Zins M, Descatha A: Work-related risk factors for lateral epicondylitis and other cause of elbow pain in the working population. Am J Ind Med 56:400-409,2013

11. Khansa I, Khansa L, Westvik TS, Ahmad J, Lista F, Janis JE: Work-related musculoskeletal injuries in plastic surgeons in the United States, Canada, and Norway. Plast Reconstr Surg 141:165e-175e,2018

12. Leclerc A, Landre MF, Chastang JF, Niedhammer I, Roquelaure Y: Upper-limb disorders in repetitive work. Scand J Work Environ Health 27:268-278,2001

13. Memon AG, Naeem Z, Zaman A, Zahid F: Occupational health related concerns among surgeons. Int J Health Sci (Qassim) 10:279-291,2016

14. Noteboom T, Cruver R, Keller J, Kellogg B, Nitz AJ: Tennis elbow: A review. J Orthop Sports Phys Ther 19:357-366,1994

15. Ono $Y$, Nakamura R, Shimaoka M, Hiruta S, Hattori Y, Ichihara G, Kamijima M, Takeuchi Y: Epicondylitis among cooks in nursery schools. Occup Environ Med 55:172-179,1998

16. Pienimaki T, Karinen P, Kemilla T, Koivukangas $P$, et al: Longterm follow-up of conservatively treated chronic tennis elbow patients. A prospective and retrospective analysis. Scand J Rehab Med 30:159-166,1998

17. Ritz BR: Humeral epicondylitis among gas- and waterworks employees. Scand J Work Environ Health 21:478-486, 1995

18. Shiri R, Viikari-Juntura E, Varonen $\mathrm{H}$, Helio "vaara M: Prevalence and determinants of lateral and medial epicondylitis: A population study. Am J Epidemiol 164:1065-1074, 2006

19. van Rijn RM, Huisstede BMA, Koes BW, Burdorf A: Associations between work-related factors and specific disorders at the elbow: A systematic literature review. Rheumatology (Oxford) 48:528-536,2009

20. Vaquero-Picado A, Barco R, Antuña SA: Lateral epicondylitis of the elbow. EFORT Open Rev 1:391-397,2017

21. Walker-Bone K, Palmer KT, Reading I, Coggon D, Cooper C: Occupation and epicondylitis: A population-based study. Rheumatology (Oxford, England) 51:305-310, 2011

22. Wuori JL, Overend TJ, Kramer JF, MacDermid J: Strength and pain measures associated with lateral epicondylitis bracing. Arch Phys Med Rehabil 79:832-837,1998 